\title{
The Activities of Antioxidant Enzymes in Response to Oxidative Stresses and Hormones in Paraquat-tolerant Rehmannia glutinosa Plants
}

\author{
Dong Geun Choi ${ }^{\S}$, Nam Hee Yoo ${ }^{\dagger}$, Chang Yeon Yu $\mathbf{u}^{\ddagger}$ Benildo de los Reyes ${ }^{\#}$ and Song Joong Yun ${ }^{\dagger, \dagger+, *}$ \\ ${ }^{\S}$ Department of Horticulture, Jeollabuk-do Agricultural Research and Extension Services, Iksan 570-704, Korea \\ 'Institute of Agricultural Science and Technology, Chonbuk National University, Chonju 561-756, Korea \\ Division of Applied Plant Sciences, Kangwon Natl University, Chunchon 200-701, Korea \\ "Department of Biological Sciences, Univ. of Maine, Orono, ME 04469-5735, USA \\ "Division of Biological Resources Sciences, Chonbuk National University, Chonju 561-756, Korea
}

Received 16 February 2004, Accepted 10 June 2004

\begin{abstract}
All members of $R$. glutinosa show the unique characteristic of intrinsic tolerance to paraquat (PQ). Antioxidant enzymes have been proposed to be the primary mechanism of PQ resistance in several plant species. Therefore, the antioxidant enzyme systems of $R$. glutinosa were evaluated by comparatively analyzing cellular antioxidant enzyme levels, and their responses of oxidative stresses and hormones. The levels of ascorbate peroxidase (APX), glutathione reductase (GR), non-specific peroxidase (POX), and superoxide dismutase (SOD) were 7.3-, 4.9-, 2.7- and 1.6-fold higher in PQ-tolerant $R$. glutinosa than in PQ-susceptible soybeans. However, the activity of catalase (CAT) was about 12-fold higher in the soybeans. The activities of antioxidant enzymes reduced after PQ treatment in the two species, with the exception of POX and SOD in $R$. glutinosa, which increased by about $40 \%$. Interestingly, the activities of APX, SOD and POX in $R$. glutinosa, relative to those in soybeans, were further increased by 49, 67 and $93 \%$ after PQ treatment. The considerably higher intrinsic levels, and increases in the relative activities of antioxidant enzymes in $R$. glutinosa under oxidative stress support the possible role of these enzymes in the PQ tolerance of $R$. glutinosa. However, the relatively lower levels of SOD versus PQ tolerance, and the mixed responses of antioxidant enzymes to stresses and hormones, suggest a possible alternative mechanism(s) for PQ tolerance in $R$. glutinosa.
\end{abstract}

Keywords: Abiotic stresses, Paraquat, Rehmannia glutinosa, Stress-related hormones

*To whom correspondence should be addressed.

Tel: 82-63-270-2508; Fax: 82-63-270-2640

E-mail: sjyun@moak.chonbuk.ac.kr

\section{Introduction}

Rehmannia glutinosa (Gaertn.) Ligosch is grown in Asia as a herb, and its roots are used for traditional medicinal purposes. Little is known about the botanical and agronomical characteristics of the species. Recently, it was found that $R$. glutinosa plants exposed to the non-selective herbicide paraquat (PQ; 1,1-dimethyl-4,4-bipyridilium) showed very high levels of tolerance to the herbicide. The plants only suffered $40 \%$ phytotoxic injury, even at a rate of $6.0 \mathrm{~kg}$ a.i. PQ/ha (Kim and Chun, 1992; Chun et al., 1997).

Six models have been proposed to explain plant resistance to PQ (Fuerst and Vaughn, 1990; Hart and DiTomaso, 1994). Interestingly, none of these models explain the PQ resistance of different plant species. Considerable direct evidence supports the role of antioxidant enzymes in this resistance, which is presumably due to the scavenging of reactive oxygen intermediates (ROIs) (Gressel, 1994; Aono et al., 1995; Allen et al., 1997; Van Breusegen et al., 1999; Gressel, 2000). The sequestration of PQ in vacuoles or other organelles has been observed in PQ-resistant barley (Lasat et al., 1997), and reduced translocation is involved in the PQ resistance of Arctotheca calendula (Soar et al., 2003). However, no study to date has indicated that altered target sites, or the detoxification of PQ are primary resistance mechanisms.

The possible involvements of proposed models of PQresistance in $R$. glutinosa were examined in an earlier study (Chun et al., 1997), and the results obtained suggested the possibility of PQ metabolism as a primary mechanism of tolerance (Chun et al., 1997). Interestingly, the possible role of antioxidant systems as primary mechanism of tolerance was indicated by the PQ-nullifying activity of acteoside (or verbascoside) isolated from this species (Chun et al., 2002). Acteoside is a potent antioxidant (Gao et al., 1999), and ability to protect against lipid peroxidation has been 
demonstrated in animal cells (Liu et al., 2003).

However, not much is known about the antioxidant systems of $R$. glutinosa as the plant has received little interest until recently. Since the role of antioxidants in PQ-tolerance has been demonstrated in the species, we considered that a more detailed characterization of the antioxidant systems in this species would provide information on its PQ-tolerance. Moreover, relative to the considerable evidence on the role of antioxidant enzymes in PQ-resistance, little is known about the antioxidant enzymes of $R$. glutinosa. Furthermore, the antioxidant systems in chloroplasts and cytoplasm are known to play roles in PQ resistance (Donahue et al., 1997; Vartak and Bhargava, 1999). Therefore, in this study we evaluated the cellular antioxidant enzyme systems of $R$. glutinosa by analyzing the responsivenesses of enzymes to oxidative stresses and hormone treatments. Since no PQ-susceptible $R$. glutinosa plants have been reported, comparative analyses were also conducted between the PQ-tolerant $R$. glutinos $a$ and the PQ-susceptible soybeans.

\section{Materials and methods}

Chemicals and enzymes All chemicals and enzymes were purchased from Sigma (St. Louis, USA), unless otherwise indicated.

Plant materials $R$. glutinosa (cv. Namwon) and soybean (cv. Danyeopkong) plants were grown under normal growing conditions in a glasshouse at Chonbuk National University, Korea. $R$. glutinosa plants were raised from tubers harvested during the previous growing season. Leaves were collected from healthy $R$. glutinosa and soybean plants grown for 2 months in a glasshouse.

Stress and hormone treatments $R$. glutinosa leaves were collected by cutting the upper part of petioles with a razor blade. Fully expanded trifoliate leaves of the soybean were collected in the same way, and each leaflet was separated with a razor blade. The leaves were then treated with sterile solutions of $5.6 \mathrm{mM}$ paraquat (PQ), $5 \mathrm{mM} \mathrm{H} \mathrm{H}_{2}, 5 \mathrm{mM}$ ethephon (ET) or $5 \mathrm{mM}$ salicylic acid (SA), for $24 \mathrm{~h}$, as previously described, (Chung et al., 2003). Each treatment was performed in triplicate.

Enzyme activity assays Total cellular extracts of each antioxidant enzyme were prepared at $4^{\circ} \mathrm{C}$, and used in activity assays. The activities of ascorbate peroxidase (APX; EC 1.11.1.11), nonspecific peroxidase (POX; EC1.11.1.7), catalase (CAT; EC 1.11.1.6), glutathione reductase (GR; EC 1.6.4.2), and superoxide dismutase (SOD; EC 1.15.1.1) were determined spectrophotometrically (Beers and Sizer, 1952; Chance and Maehly, 1955; Nakano and Asada, 1981; O'Kane et al., 1996; Baek et al., 2000; Lee, et al., 2003; Yun and Lee, 2003). APX activity was determined after oxidizing ascorbate to dehydroascorbate, as described by Nakano and Asada (1981). The extraction buffer contained $50 \mathrm{mM}$ phosphate, $0.5 \mathrm{mM}$ ascorbate, $0.1 \mathrm{mM}$ EDTA, and $1 \%(\mathrm{w} / \mathrm{v})$ polyvinylpolypyrrolidone (PVPP), at $\mathrm{pH} 7.0$, and the assay mixture $50 \mathrm{mM}$ phosphate, $0.5 \mathrm{mM}$ ascorbate, $0.1 \mathrm{mM}$ EDTA and $0.1 \mathrm{mM}$ $\mathrm{H}_{2} \mathrm{O}_{2}$, at $\mathrm{pH}$ 7.0. The extraction buffer for POX contained $100 \mathrm{mM}$ phosphate, $1 \mathrm{mM}$ EDTA, $1 \mathrm{mM}$ phenylmethylsulfonyl fluoride (PMSF), and 1\% (w/v) PVPP, at $\mathrm{pH} 7.8$, and the assay mixture 50 $\mathrm{mM}$ phosphate, $10 \mathrm{mM}$ guaiacol, and $100 \mathrm{mM} \mathrm{H}_{2} \mathrm{O}_{2}$, at $\mathrm{pH} 6.4$ (Chance and Maehly, 1955). The extraction buffer for the CAT assay contained $100 \mathrm{mM}$ phosphate, $1 \mathrm{mM}$ EDTA, $1 \mathrm{mM}$ PMSF and $1 \%(\mathrm{w} / \mathrm{v}) \mathrm{PVPP}$, at $\mathrm{pH} 7.8$, and the assay mixture $50 \mathrm{mM}$ phosphate and $11.6 \mathrm{mM} \mathrm{H}_{2} \mathrm{O}_{2}$, at pH 6.9 (Beers and Sizer, 1952). The extraction buffer for GR assay contained $50 \mathrm{mM}$ phosphate, $0.1 \mathrm{mM}$ EDTA, $1 \mathrm{mM}$ ascorbate and 1\% (w/v) PVPP, at $\mathrm{pH} 7.0$, and the assay mixture $100 \mathrm{mM}$ Tris- $\mathrm{HCl}, 2 \mathrm{mM}$ EDTA, $0.05 \mathrm{mM}$ NADPH and $0.5 \mathrm{mM}$ oxidized glutathione, at pH 7.8 (O'Kane et al., 1996). The extraction buffer for SOD contained $100 \mathrm{mM}$ phosphate, $10 \mathrm{mM}$ sodium ascorbate, $5 \mathrm{mM}$ diethylene triaminepentaacetic acid (DTPA), and 1\% (w/v) PVPP, at $\mathrm{pH} 7.0$, and the assay mixture $50 \mathrm{mM}$ phosphate, $1.8 \mathrm{mM}$ xanthine, $0.05 \mathrm{mM}$ nitroblue tetrazolium, $1 \mathrm{mM}$ DTPA, 1 unit/ml catalase, and $0.01 \mathrm{unit} / \mathrm{ml}$ xanthine oxidase, at pH 7.8 (Obeley and Spitz, 1984). CuZn-SOD activity was determined after extracting enzyme solutions with chloroform/ alcohol $(\mathrm{v} / \mathrm{v}=37.5: 63.5)$ (Nobet et al., 1993), and the protein contents of the enzyme extracts by the Bradford (1979) method. Assays were conducted in triplicate and enzyme activity data were analyzed using SAS (SAS Institute Inc., Cary, USA).

\section{Results}

Ascorbate peroxidase activity Specific APX activities showed characteristic responses to stresses and hormones in both plant species. In $R$. glutinosa this activity was reduced by $\mathrm{PQ}, \mathrm{SA}$, or ET treatment. No significant changes were observed after $\mathrm{H}_{2} \mathrm{O}_{2}$ treatment. Conversely, the activity of soybean was increased by adding ET or SA, but reduced by PQ treatment. These increased activity levels of soybean were less than $25 \%$ of those of $R$. glutinosa, and activity was decreased by about $50 \%$ by PQ treatment (Fig. 1). Comparisons between the two species indicated that the activity of $R$. glutinosa was more than 7-fold that of soybean, and its activity was about 11-fold higher than that of soybean after PQ treatment, but about 2.2- and 1.3-fold higher after ET or SA treatment.

Non-specific peroxidase activity The POX activities of the two species responded differently to all treatments. In $R$. glutinosa, POX activities were increased by $\mathrm{H}_{2} \mathrm{O}_{2}$ and PQ, but were decreased by ET or SA. The activities in soybean were increased by SA or ET, but were decreased by $\mathrm{H}_{2} \mathrm{O}_{2}$ or PQ treatment. This decrease in activity was greatest $(27 \%)$ for PQ (Fig. 2). Comparisons between the two species indicated that the POX activity of $R$. glutinosa was 2.7-fold that of soybean. The activity of $R$. glutinosa was 5.3- or 3.3-fold higher than that of the soybeans after PQ or $\mathrm{H}_{2} \mathrm{O}_{2}$ treatment, respectively, but 0.1 -fold higher after $\mathrm{SA}$ treatment.

Superoxide dismutase activity The responses of specific total SOD activities to stresses and hormones were quite different in the two plant species. The activity in $R$. glutinosa was increased by $\mathrm{PQ}, \mathrm{H}_{2} \mathrm{O}_{2}, \mathrm{ET}$, or SA. In soybean, SOD 


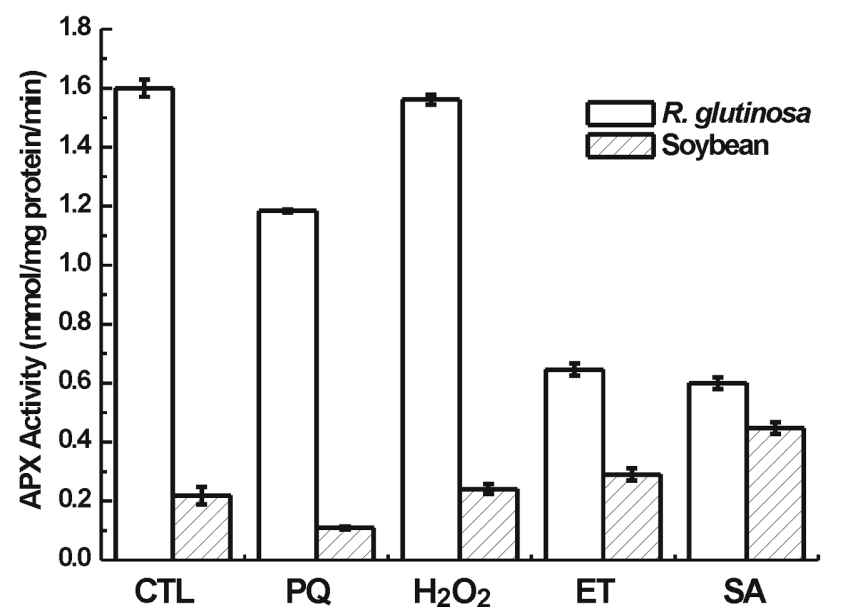

Fig. 1. The activities of APX in response to oxidative stresses and hormones in R. glutinosa and soybeans. CTL, control; PQ, $5.6 \mathrm{mM}$ paraquat; $\mathrm{H}_{2} \mathrm{O}_{2}, 5 \mathrm{mM}$ hydrogen peroxide; ET, $5 \mathrm{mM}$ ethephon, and SA, $5 \mathrm{mM}$ salicylic acid. In a pair-wise comparison between species for each treatment. Enzyme activities in $R$. glutinosa and soybean differed significantly for all treatments $(p=0.05)$. Treatments produced significantly different enzyme activities effects in both species, with the exception of $\mathrm{H}_{2} \mathrm{O}_{2}$.

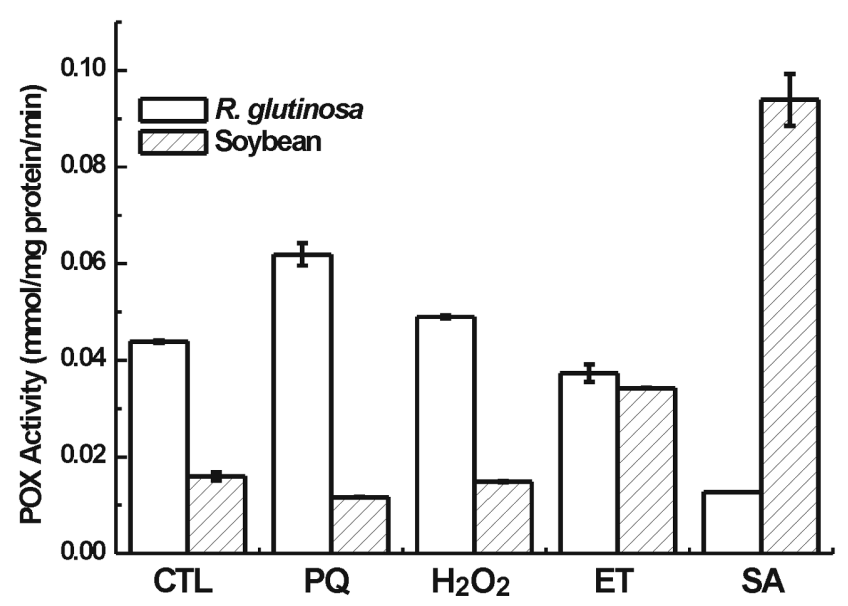

Fig. 2. The POX activities in response to oxidative stresses and hormones in R. glutinosa and soybeans. CTL, control; PQ, 5.6 $\mathrm{mM}$ paraquat; $\mathrm{H}_{2} \mathrm{O}_{2}, 5 \mathrm{mM}$ hydrogen peroxide; ET, $5 \mathrm{mM}$ ethephon and SA, $5 \mathrm{mM}$ salicylic acid. Enzyme activities in both species differed significantly for all treatments $(p=0.05)$, and each treatment induced significantly different enzyme activities, with the exception of $\mathrm{H}_{2} \mathrm{O}_{2}$ in soybean.

activity was reduced by $\mathrm{PQ}$, but was increased by SA. Activity remained was unchanged by $\mathrm{H}_{2} \mathrm{O}_{2}$ or ET (Fig. 3). Total SOD activity in $R$. glutinosa was $>1.6$-fold greater than in soybean. The total activity of $R$. glutinos $a$ was 2.7-fold higher than that of soybean after PQ, and 2.3-fold was higher after $\mathrm{H}_{2} \mathrm{O}_{2}$ or ET, and 1.2-fold higher after SA. CuZn-SOD activity increased in the same way as total SOD activity by the treatments in both species. CuZn-SOD activity accounted for 82 and $71 \%$ of the total SOD activity of $R$. glutinosa and soybean, respectively.

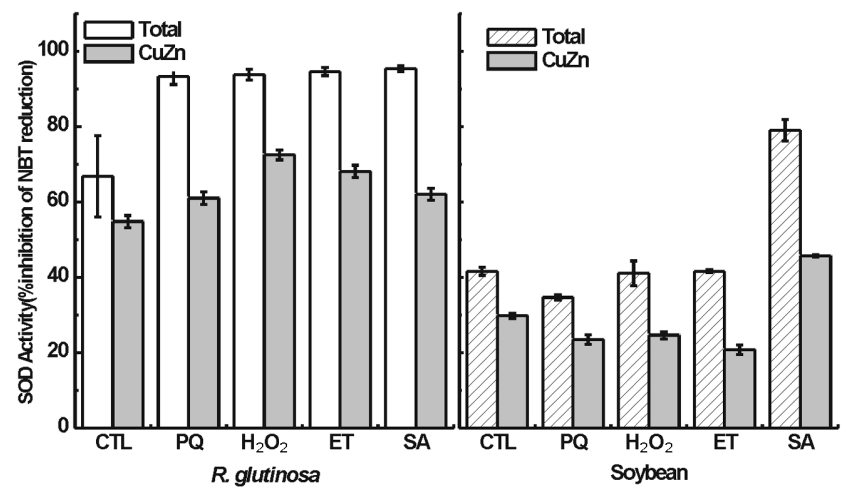

Fig. 3. Total SOD and CuZn-SOD activity in response to oxidative stresses and hormones in $R$. glutinosa and soybeans. CTL, control; PQ, $5.6 \mathrm{mM}$ paraquat; $\mathrm{H}_{2} \mathrm{O}_{2}, 5 \mathrm{mM}$ hydrogen peroxide; ET, $5 \mathrm{mM}$ ethephon and SA, $5 \mathrm{mM}$ salicylic acid. Enzyme activities in $R$. glutinosa and soybean differed significantly for all treatments $(\mathrm{p}=0.05)$, and within species, enzyme activities were affected significantly by each treatment, with the exception of $\mathrm{H}_{2} \mathrm{O}_{2}$ and ET in soybean.

The ratio of $\mathrm{CuZn-SOD}$ activity to total activity was decreased by 5 to $16 \%$ in $R$. glutinosa and by 3 to $21 \%$ in soybean by the treatments (Fig. 3), suggesting that other types of SOD isoforms, like Mn-SOD and Fe-SOD, have an increased role under stress conditions. However, the ratio of $\mathrm{CuZn-SOD}$ activity to total activity was higher in $R$. glutinosa than in soybean (Fig. 3). In $R$. glutinosa, the ratio was higher than $65 \%$ after all treatments, indicating its major contribution to total superoxide scavenging activity under conditions of stress.

Glutathione reductase activity GR activity responded to stress and hormone treatments in a similar manner in both species. In $R$. glutinosa, GR activity increased dramatically in response to ET or SA, and was reduced by $\mathrm{H}_{2} \mathrm{O}_{2}$ or PQ. In soybean, GR activity was increased by ET and SA. However, its activity was reduced by $\mathrm{H}_{2} \mathrm{O}_{2}$ and PQ (Fig. 4), and in $R$. glutinosa, this reduced activity was highest (23\%) for PQ. Comparisons of activities between the two species indicated that activity in $R$. glutinosa was 4.9-fold higher than that in soybean. The activity of $R$. glutinosa was 31.8 -fold higher than that of soybean treated with ET, but 3.5-fold higher after PQ treatment.

Catalase activity In contrast to the other enzymes, CAT activity was higher in soybean. The response of this enzyme was different for all treatments, except for PQ. In R. glutinosa, CAT activity was increased by SA or ET, and was decreased by $\mathrm{H}_{2} \mathrm{O}_{2}$ or PQ treatment. In soybean, the activity was unchanged by $\mathrm{H}_{2} \mathrm{O}_{2}$, but reduced by PQ, ET or SA (Fig. 5). Comparisons of activity between the two species indicated that CAT activity in soybean is about 12-fold higher than that of $R$. glutinosa. However, the activity of soybeans was 26-fold higher than that of $R$. glutinosa after PQ or $\mathrm{H}_{2} \mathrm{O}_{2}$ treatment, but 6.9- or 0.9-fold higher after ET or SA treatment. 


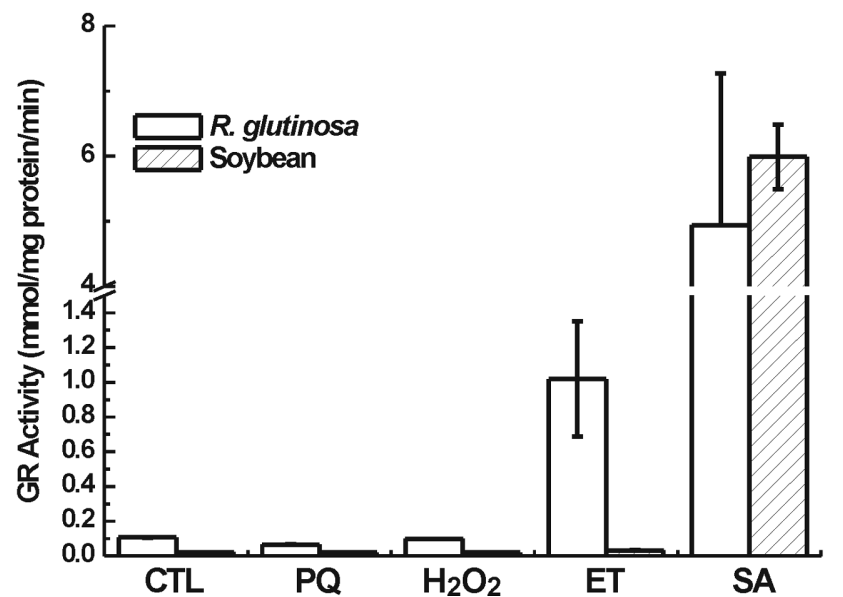

Fig. 4. The GR activities in response to oxidative stresses and hormones in R. glutinosa and soybeans. CTL, control; PQ, 5.6 $\mathrm{mM}$ paraquat; $\mathrm{H}_{2} \mathrm{O}_{2}, 5 \mathrm{mM}$ hydrogen peroxide; ET, $5 \mathrm{mM}$ ethephon and SA, and $5 \mathrm{mM}$ salicylic acid. Enzyme activities differed between species for all treatments, except for SA $(p=0.05)$. And, within species enzyme activities were changed significantly by ET and SA in $R$. glutinosa and by SA in soybean versus the control.

\section{Discussion}

It is well established that ROIs and antioxidant enzymes play important roles in the establishment of normoxia in biologic systems and in the resistance to oxidative stress (Mittler, 2002). The dual roles of ROIs, as toxic and signaling molecules, are ensured by the complex but elaborate systems controlling intracellular ROI levels (Mittler, 2002). The ROIs are detoxified by single, or a series of antioxidant enzyme reactions. The superoxide generated by $\mathrm{PQ}$ and by other causes, is dismutated to $\mathrm{H}_{2} \mathrm{O}_{2}$ and oxygen by SOD, and this $\mathrm{H}_{2} \mathrm{O}_{2}$ is then removed by a family of peroxidases. $\mathrm{H}_{2} \mathrm{O}_{2}$ is converted to water by APX in concert with the oxidation of ascorbate, and also by GPX with the oxidation of glutathione, in the cytosol and chloroplasts (Asada and Takahashi, 1987). The glutathione cycle is continued by the reduction of oxidized glutathione by GR (Dixon et al., 1998). $\mathrm{H}_{2} \mathrm{O}_{2}$ is also converted to water and oxygen by the two-electron dismutation of CAT in peroxisomes (Willekens et al., 1997). Therefore, the capacity of an antioxidant enzyme system is determined by the concerted action of the enzymes involved in the successive steps of conversion and detoxification. The importance of the coordinated induction of a group of antioxidant enzymes in PQ resistance has been demonstrated in C. bonariensis (Gressel, 2000).

As expected, the levels of APX, GR, POX, and SOD were all higher, by 7.3-, 4.9-, 2.7- and 1.6-fold, respectively, in PQtolerant $R$. glutinosa than in the PQ-susceptible soybean (Figs $1,2,3$, and 4). However, the activity of CAT was about 12fold higher in soybean (Fig. 5). Higher levels of PQ resistance have been attributed to elevated levels of antioxidant enzymes

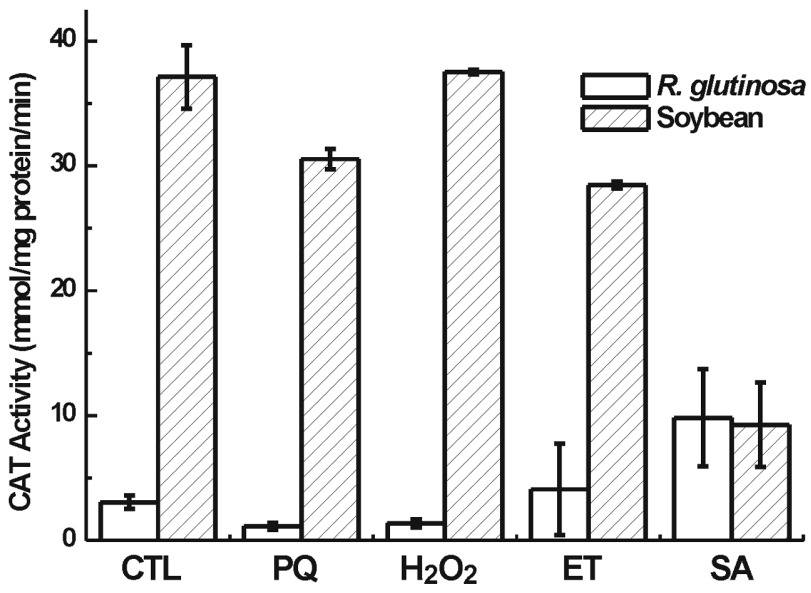

Fig. 5. CAT activities in response to oxidative stresses and hormones in $R$. glutinosa and soybean. CTL, control; PQ, 5.6 $\mathrm{mM}$ paraquat; $\mathrm{H}_{2} \mathrm{O}_{2}, 5 \mathrm{mM}$ hydrogen peroxide; ET, $5 \mathrm{mM}$ ethephon and SA, $5 \mathrm{mM}$ salicylic acid. Enzyme activities changes in the two species were significantly different for all treatments, with the exception of SA $(p=0.05)$. And within species enzyme activities were changed significantly by each treatment, with the exception of $\mathrm{H}_{2} \mathrm{O}_{2}$ in $R$. glutinosa, and by ET in soybean.

in many plant species. In $C$. bonariensis, the activities of APX, SOD, and GR were found to be about 30 to $50 \%$ higher in the total cell extracts of a PQ-resistant biotype than in a PQsusceptible biotype (Gressel, 2000).

Activities in response to stresses and hormones were different in $R$. glutinos $a$ and the soybean for all enzymes, with the exception of GR, and the activities of these enzymes were reduced by PQ in both plant species, except POX and SOD in $R$. glutinosa, whose activities increased by about $40 \%$. Differential responses of antioxidant enzymes to PQ are often noticed within and among plant species. In C. bonariensis, PQ-induced increases in APX, SOD and GR were observed only in the PQ-resistant biotype (Gressel, 2000). Similarly, PQ treatments resulted in increased SOD in maize (Matters and Scandalios, 1986) and wheat seedlings (Okuda et al., 1992). In tobacco, however, the responses of SOD expression to PQ differed in the two species. The abundance of Fe-SOD mRNA was increased in response to PQ in N. plumbaginifolia (Tsang et al., 1991), but reduced in N. tabacum (Kurepa et al., 1997).

The activities of enzymes in response to $\mathrm{H}_{2} \mathrm{O}_{2}$ are also different in plant species. In $R$. glutinosa, $\mathrm{H}_{2} \mathrm{O}_{2}$ caused increases in POX and SOD, little change in APX, but reduced both GR and CAT activity. In soybean, the responses of POX, SOD, and CAT contrasted those in the $R$. glutinosa. It is known that metalloenzymes, such as $\mathrm{CuZn-SOD}$ and APX, are inactivated by $\mathrm{H}_{2} \mathrm{O}_{2}$ in tobacco and spinach (Miyagawa et al., 2000; Mano et al., 2001). Conversely, $\mathrm{H}_{2} \mathrm{O}_{2}$ treatment increased both APX and SOD activity in Arabidopsis (Rao et al., 1997).

The responses of antioxidant enzymes to ET show enzymespecific differences, according to plant species. In $R$. 
glutinosa, ET reduced both APX and POX activity, but increased SOD, GR, and CAT activity. As in R. glutinosa, ET treatment rapidly reduced the level of APX in spinach (Hodges and Forney, 2000), and as was found in soybean, ET increases APX activity in mung beans and peas (Melhorn, 1990), but reduces CAT activity in cut carnations (Sylvestre $e t$ al., 1989). However, unlike observations in R. glutinosa and soybean, ET treatment reduced both SOD and GR activity in cut carnations (Sylvestre et al., 1989), but caused no change in SOD activity in spinach (Hodges and Forney, 2000).

Differential responses of antioxidant enzymes to SA are not rare. Acute treatment with SA induced no major influence on foliar CAT activities in Arabidopsis (Summer-Matter et al., 1995), but prolonged SA treatment inactivated APX and CAT activities (Rao et al., 1997). In rice, however, response to SA was diverse among antioxidant enzymes: the activities of GR, SOD, and POX were increased, unchanged, and inhibited, respectively, by SA treatment (Ganesan and Thomas, 2001). In tobacco, SA treatment induced GR and SOD, but not CAT activity (Fodor et al., 1997).

The responses of antioxidant enzymes to stresses and hormones might be related to species characteristic antioxidant systems profiles and hormone levels. Dramatic contrasts were found between APX and CAT activities in $R$. glutinosa and soybean: APX activity was over 7-fold higher in $R$. glutinos, but CAT activity was 12 -fold higher in soybean. This suggests that plant species use different enzymes as primary defenses against $\mathrm{H}_{2} \mathrm{O}_{2}$, and these may require different regulatory systems (Mittler, 2002). The responses of APX and CAT activities to SA and ET in the two species clearly contrasted. The differential responses of antioxidant enzymes to SA treatment in rice and tobacco were attributed to a two orders of magnitude difference in leaf SA concentrations (Ganesan and Thomas, 2001).

Since the herbicidal activity of PQ is related to superoxide production (Preston, 1994), it seems reasonable that plants showing tolerance to PQ should have mechanism(s) capable of reducing the harmful effects of this radical. And, elevated levels of SOD have beeen found to be correlated with higher resistance to PQ in several plant species (Norman et al., 1993; Danahue et al., 1997; Gressel, 2000). In addition, it has been reported that the tolerance of $R$. glutinosa to PQ is about 9fold higher than in soybean (Chun et al., 1997). Relative to the levels of tolerance of $R$. glutinosa to PQ, the two- to three-fold higher SOD activities in $R$. glutinosa versus soybean, may mitigate against SOD as being a primary player in the removal of PQ-generated superoxide. Nevertheless, considerably higher levels of activity may support a supplementary role for SOD in the PQ tolerance of $R$. glutinosa. In spinach, APX is the primary target of methylvilogen-induced oxidative damage (Mano et al., 2001). Therefore, the 7- to 11-fold higher total APX activity exhibited by $R$. glutinosa versus soybean without and with paraquat treatment, has a significant implication with respect to the paraquat tolerance of the species. Since $\mathrm{H}_{2} \mathrm{O}_{2}$ freely diffuses through membranes
(Willekens et al., 1997), cytosolic $\mathrm{H}_{2} \mathrm{O}_{2}$-scavanging enzymes can help protect chloroplasts from high concentrations of $\mathrm{H}_{2} \mathrm{O}_{2}$. Furthermore, increases in SOD and POX activities, with no inactivation of APX in $R$. glutinosa by $\mathrm{H}_{2} \mathrm{O}_{2}$ (Figs 1,2 , and 3 ), may ensure the efficient detoxification of $\mathrm{H}_{2} \mathrm{O}_{2}$, and thereby contribute to the PQ tolerance of the species. The possible contribution of antioxidant enzymes to $\mathrm{PQ}$ tolerance in $R$. glutinosa is further supported by significant increases in the relative activities of antioxidant enzymes in $R$. glutinosa versus soybean after PQ treatment (Figs 1, 2, 3, 4, and 5).

The significance of antioxidant enzymes in PQ resistance has also been demonstrated using transgenic plants. Increased expressions of SOD, APX, or GR, in the cytosol or chloroplast, provide plants with increased PQ resistance (Aono et al., 1995; Allen et al., 1997; Van Breusegem et al., 1999). Interestingly, however, the suppression of APX and CAT activates metabolic and defense genes, which coupled with the inhibition of photosynthetic activity compensate for the lack of APX and CAT, suggesting a plasticity and diversity of responses to different oxidative stresses (Rizhsky et al., 2002). Therefore, the possibility of alternative mechanisms of PQ tolerance cannot be ruled out. Together with enzymatic antioxidant defense systems, non-enzymatic systems also contribute to the scavenging of ROIs. Non-enzymatic systems include ascorbate, glutathione, alpha-tocopherol, and phenolic compounds, such as flavonoids, tannins and lignin precursors (Foyer et al., 1994; Rice-Evans et al., 1997). The PQnullifying activity of the phenolic compound acteoside, isolated from $R$. glutinosa, strongly suggests the involvement of non-enzymatic antioxidant systems in the PQ tolerance of R. glutinosa (Chun et al., 2002). Therefore, the mixed responses of antioxidant enzymes to stresses and hormones may reflect response plasticity to oxidative stress and provides an insight into the complexities of $\mathrm{PQ}$ tolerance in $R$. glutinosa.

Acknowledgments This work was supported by a grant from BioGreen 21 Program, Rural Development Administration, Republic of Korea.

\section{References}

Allen, R. D., Webb, R. P. and Schake, S. A. (1997) Use of transgenic plants to study antioxidant defense. Free Rad. Biol. Med. 23, 473-479.

Aono, M., Saji, H., Sakamoto, A., Tanaka, K., Kondo, N. and Tanaka, K. (1995) Paraquat tolerance of transgenic Nicotiana tabacum with enhanced activities of glutathione reductase and superoxide dismutase. Plant Cell Physiol. 36, 1687-1691.

Asada, K. and Takahashi, M. (1987) Production and scavenging of active oxygen in photosynthesis; in Photoinhibition, Kyle, D. J., Osmond, C. B. and Arntzen, C. J. (eds.), pp. 227-287, Elsevier, Amsterdam, Netherlands.

Baek, S. H., Kwon, I. S., Park T. I., Yun, S. J., Kim, J. K. and Choi, K. G. (2000) Activities and isozyme profiles of 
antioxidant enzymes in intercellular compartment of overwintering barley leaves. J. Biochem. Mol. Biol. 33, 385390.

Beers, R. F. and Sizer, I. W. (1952) A spectrophotometric method for measuring the breakdown of hydrogen peroxide by catalase. J. Biol. Chem. 195, 133-140.

Bradford, M. M. (1979) A rapid and sensitive method for the quantitation of microgram quantities of protein utilizing the principle of protein-dye binding. Anal. Biochem. 72, 248-254.

Chance, B. and Maehly, A. C. (1955) Assay of catalase and peroxidase. Methods Enzymol. 2, 764-775.

Chun, J. C., Kim, J. C., Hwang, I. T. and Kim, S. E. (2002) Acteoside from Rehmannia glutinosa nullifies paraquat activity in Cucumis sativus. Pestic. Biochem. Physiol. 72, 153-159.

Chun, J. C., Ma, S. Y., Kim, S. E. and Lee, H. J. (1997) Physiological responses of Rehmannia glutinosa to paraquat and its tolerance mechanisms. Pestic. Biochem. Physiol. 59, 5163.

Chung, I. M., Park, M. R., Chun, J. C. and Yun, S. J. (2003) Resveratrol accumulation and resveratrol synthase gene expression in response to abiotic stresses and hormones in peanut plants. Plant Sci. 164, 103-109.

Dixon, D., Cummins, I., Cole, D. J. and Edwards, R. (1998) Glutathione-mediated detoxification systems in plants. Curr. Opin. Plant Biol. 1, 258-266.

Donahue, J. L., Okpodu, C. M., Cramer, C. L., Grabau, E. A. and Alscher, R. G. (1997) Response of antioxidants to paraquat in pea leaves. Relationships to resistance. Plant Physiol. 113, 249257.

Fodor, J., Gullner, G., Adam, A. L., Barna, B., Komives, T. and Kiraly, Z. (1997) Local and systemic responses of antioxidants to tobacco mosaic virus infection and to salicylic acid in tobacco. Role in systemic acquired resistance. Plant Physiol. 114, 1443-1451.

Foyer, C., Descourvieres, P, and Kunert, K. J. (1994) Protection against oxygen radicals: an important defense mechanism studied in transgenic plants. Plant Cell Environ. 17, 507-523.

Fuerst, E. P. and Vaughn, K. C. (1990) Mechanisms of paraquat resistance. Weed Technol. 4, 150-156.

Ganesan, V. and Thomas, G. (2001) Salicylic acid response in rice: influence of salicylic acid on $\mathrm{H}_{2} \mathrm{O}_{2}$ accumulation and oxidative stress. Plant Sci. 160, 1095-1106.

Gao, J. J., Igalashi, K. and Nukina, M. (1999) Radical scavenging activity of phenylpropanoid glycosides in Caryopteris incana. Biosci. Biotech. Biochem. 63, 983-988.

Hart, J. J. and DiTomaso, M. (1994) Sequestration and oxygen radical detoxification as mechanisms of paraquat resistance. Weed Sci. 42, 277-284.

Hodges, D. M. and Forney, C. F. (2000) The effects of ethylene, depressed oxygen and elevated carbon dioxide on antioxidant profiles of senescing spinach leaves. J. Exp. Bot. 51, 645-655.

Kim, J. S. and Chun, J. C. (1992) Resistance of the medicinal plant jiwhang (Rehmannia glutinosa) to paraquat. Korean $J$. Weed Sci. 12, 374-378.

Kurepa, J., Herouart, D., Van Montagu, M. and Inze, D. (1997) Differential expression of $\mathrm{CuZn}$ - and $\mathrm{Fe}$-superoxide dismutase genes of tobacco during development, oxidative stress, and hormonal treatments. Plant Cell Physiol. 38, 463-470.

Lasat, M. M., DiTomaso, J. M., Hart, J. J. and Kochian, L. V. (1997) Evidence for vacuolar sequestration of paraquat in roots of a paraquat-resistant Hordeum glaucum biotype. Physiol. Plant. 99, 255-262.

Lee, H. Y., Eum, W. S., Kim, D. W., Lee, B. R., Yoon, C. S., Jang, S. H., Choi, H. S., Choi, S. H., Baek, N.-I., Kang, J. H., Kang, T.-C., Won, M. H., Cho, S.-W., Lee, K. S., Park, J., and Choi, S. Y. (2003) Isolation and Identification of an Antioxidant Enzyme Catalase Stimulatory Compound from Garnoderma lucidum. J. Biochem. Mol. Biol. 36, 450 455.

Liu, M. J., Li, K. X., Guo, H. Z., Lee, K. M., Qin, L. and Chan, K. M. (2003) The effects of verbascoside on plasma lipid peroxidation level and erythrocyte membrane fluidity during immobilization in rabbits: a time course study. Life Sci. $\mathbf{7 3 ,}$ 883-892.

Mano, J., Ohno, C., Domae, Y. and Asada, K. (2001) Chloroplastic ascorbate peroxidase is the primary target of methylviologen-induced photooxidative stress in spinach leaves: its relevance to monodehydroascorbate radical detected with in vivo ESR. Biochem. Biophys. Acta. 1504, 275-287.

Matters, G. L. and Scandalios, J.G. (1986) Effect of the free radical-generating herbicide paraquat on the expression of the superoxide dismutase (Sod) genes in maize. Biochim. Biophys. Acta. 3, 29-38.

Melhorn, H. (1990) Ethylene-promoted ascorbate peroxidase activity protects plants against hydrogen peroxide, ozone and paraquat. Plant Cell Environ. 13, 971-976.

Mittler, R. (2002) Oxidative stress, antioxidants and stress tolerance. Trends Plant Sci. 7, 405-410.

Miyagawa, Y., Tamoi, M. and Shigeoka, S. (2000) Evaluation of the defense system in chloroplasts to photooxidative stress caused by paraquat using transgenic tobacco plants expressing catalase from Escherichia coli. Plant Cell Physiol. 41, 311-320.

Nakano, Y. and Asada, K. (1981) Hydrogen peroxide is scavenged by ascorbate-specific peroxidase in spinach chloroplasts. Plant Cell Physiol. 22, 867-880.

Norman, M. A., Fuerst, E. P., Smeda, R. J. and Vaughn, K. C. (1993) Evaluation of paraquat resistance mechanisms in Conyza. Pestic. Biochem. Physiol. 46, 236-249.

Nebot, C., Moutet, M., Huet, P., Xu, J. Z., Yadan, J. C. and Chaudiere, J. (1993) Spectrophotometric assay of superoxide dismutase activity based on the activated autoxidation of a tetracyclic catechol. Anal. Biochem. 214, 442-452.

Oberley, L. W. and Spitz, D. R. (1984) Assay of superoxide dismutase activity in tumor tissue. Methods Enzymol. 105, 457464.

O'Kane, D., Gill, V., Boyd, P. and Burdon, R. (1996) Chilling, oxidative stress and antioxidant responses in Arabidopsis thaliana callus. Planta 198, 371-377.

Okuda, T., Matsuda, Y., Sugawara, M. and Sagisaka, S. (1992) Metabolic response to treatment with cold, paraquat, or 3amino-1,2,4-triazole in leaves of winter wheat. Biosci. Biotechnol. Biochem. 56, 1911-1915.

Preston, C. (1994) Resistance to photosystem I disrupting herbicides; in Herbicide Resistance in Plants: Biology and Biochemistry, Powles, S. B. and Holtum, J. A. M. (eds.), pp. 61-82, Lewis Publishers, Boca Raton, USA.

Rao, M. V., Paliyath, G., Ormrod, D. P., Murr, D. P. and Watkins, C. B. (1997) Influence of salicylic acid on $\mathrm{H}_{2} \mathrm{O}_{2}$ production, oxidative stress, and $\mathrm{H}_{2} \mathrm{O}_{2}$-metabolizing enzymes. Salicylic acid-mediated oxidative damage requires $\mathrm{H}_{2} \mathrm{O}_{2}$. Plant Physiol. 115, 137-149. 
Rice-Evans, C. A., Miller, N. J. and Paganga, G. (1997) Antioxidant properties of phenolic compounds. Trends Plant Sci. 2, 152-159.

Rizhsky, L., Hallak-Herr, E., Van Breusegem, F., Rachmilevitch, S., Barr, J. E., Rodermel, S., Inze, D. and Mittler, R. (2002) Double antisense plants lacking ascorbate peroxidase and catalase are less sensitive to oxidative stress than single antisense plants lacking ascorbate peroxidase or catalase. Plant J. 32, 329-342.

Soar, C. J., Karotam, J., Preston, C. and Powles, S. B. (2003) Reduced paraquat translocation in paraquat resistant Arctotheca calendula (L.) Levyns is a consequence of the primary resistance mechanism, not the cause. Pestic. Biochem. Physiol. 76, 91-98.

Summer-Matter, K., Sticher, L. and Metraux, J. P. (1995) Systemic response in Arabidopsis thaliana infected and challenged with Pseudomonas syringae pv syringae. Plant Physiol. 108, 13791385.

Sylvestre, I., Droillard, M. J., Bureau, J. M. and Paulin, A. (1989) Effects of the ethylene rise on the peroxidation of membrane lipids during the senescence of cut carnations. Plant Physiol. Biochem. 27, 407-413.

Tsang, E. W., Bowler, C., Herouart, D., Van Camp, W., Villarroel, R., Genetello C., Van Montagu, M. and Inze, D. (1991) Differential regulation of superoxide dismutases in plants exposed to environmental stress. Plant Cell 3, 783-792.

Van Breusegem, F,. Slooten, L., Stassart, J. M., Moens, T., Botterman, J., Van Montagu, M. and Inze, D. (1999) Overproduction of Arabidopsis thaliana FeSOD confers oxidative stress tolerance to transgenic maize. Plant Cell Physiol. 40, 515-523.

Vartak, V. and Bhargava, S. (1999) Photosynthetic performance and antioxidant metabolism in a paraquat-resistant mutant of Chlamydomonas reinhardtii L. Pestic. Biochem. Physiol. 64, 915.

Willekens, H., Chamnongpol, S., Davey, M., Schraudner, M., Langebartels, C., Van Montagu, M. and Van Camp, W. (1997) Catalase is a sink for $\mathrm{H}_{2} \mathrm{O}_{2}$ and is indispensable for stress defense in C-3 plants. EMBO J. 16, 4806-4816.

Ye, B. and Gressel, J. (1994) Constitutive variation of ascorbate peroxidase activity during development parallels that of superoxide dismutase and glutathione reductase in paraquatresistant Conyza. Plant Sci. 102, 147-151.

Ye, B. and Gressel, J. (2000) Transient, oxidant-induced antioxidant transcript and enzyme levels correlate with greater oxidant-resistance in paraquat-resistant Conyza bonariensis. Planta 211, 50-61.

Yun, Y. S. and Lee, Y. N. (2003) Production of superoxide dismutase by Deinococcus radiophilous. J. Biochem. Mol. Biol. 36, 282-287. 